\title{
THE
}

1990

\section{Deep-Ocean Bottom Pressure Measurement: Drift Removal and Performance}

D. Randolph Watts

University of Rhode Island, randywatts@uri.edu

Harilaos Kontoyiannis

University of Rhode Island

Follow this and additional works at: https://digitalcommons.uri.edu/gsofacpubs

\section{Citation/Publisher Attribution}

Watts, D. R., \& Kontoyiannis, H. (1990). Deep-Ocean Bottom Pressure Measurement: Drift Removal and Performance. J. Atmos. Oceanic Technol, 7(2), 296-306. doi: 10.1175/1520-0426(1990)0072.0.C0;2 Available at: https://doi.org/10.1175/1520-0426(1990)007<0296:DOBPMD>2.0.C0;2

This Article is brought to you for free and open access by the Graduate School of Oceanography at DigitalCommons@URI. It has been accepted for inclusion in Graduate School of Oceanography Faculty Publications by an authorized administrator of DigitalCommons@URI. For more information, please contact digitalcommons@etal.uri.edu. 


\title{
Deep-Ocean Bottom Pressure Measurement: Drift Removal and Performance
}

\author{
D. RANDOLPH WATTS AND HARILAOS KONTOYIANNIS \\ University of Rhode Island, Graduate School of Oceanography, Narragansett, Rhode Island
}

(Manuscript received 23 March 1989, in final form 22 September 1989)

\begin{abstract}
Sixteen records from seven Digiquartz deep-ocean bottom pressure sensors have obtained in deployments of 3-12 month duration under the Gulf Stream in depths of 3300 to $4400 \mathrm{~m}$. Particular attention is given (i) to characterizing any observed drift in their calibration in relation to their construction (bellows or Bourdontube) and to their prior history of pressurization, and (ii) to estimating and removing this drift from the records. Bellows-type sensors exhibited significant drift $(0.2$ to $0.85 \mathrm{db})$ in all of their deployments. Bourdon-tube sensors had less drift in their first deployment $(0$ to $0.45 \mathrm{db})$, and in subsequent deployments had either no drift or a small drift with different shape that may have been due to clock-frequency drift. An exponential decay with time $[\sim \exp (-\alpha t)]$ was found to best represent the drifts; such a curve was fit in a least-squares sense to each pressure record and then subtracted from it. Careful attention is given to estimating the uncertainty of the residual "dedrifted" records, which is $0.02 \mathrm{db}$ for records that are at least a year long; the stability over a few days and resolution of these measurements is better than $0.001 \mathrm{db}$. As a consistency check, neighboring pairs of bottom pressure records are used to calculate geostrophic currents from their differences, and the comparison with directly observed currents confirms that the error in drift removal may be less than $0.02 \mathrm{db}$. Typical amplitudes of the deep-ocean tidal- and detided signals are respectively 0.7 and $0.13 \mathrm{db}$ in this region, so that we infer that this methodology is suitable for studies requiring knowledge of deep-ocean dynamic pressures even for subtidal mesoscale periodicities.
\end{abstract}

\section{Introduction}

Physical oceanographers have long desired to have instrumentation capable of accurately monitoring the variations in bottom pressures in the deep ocean (e.g., Baker 1969; Baker 1981) in order to observe the oceanic pressure field in analogy with the use of barometers by meteorologists. The measurement problem has been particularly challenging at low frequencies because the subtidal dynamic pressure fluctuations are only $\sim 0.10$ to $0.01 \mathrm{db}$ in an ambient pressure of 4000 $\mathrm{db}$, requiring resolution and stability of $\sim 1 \mathrm{ppm}$.

It has not been possible to measure the absolute pressure field in the deep ocean, because the absolute elevation of the sensors relative to the geoid cannot be determined with sufficient accuracy. However, even if we must exclude the mean field, much valuable information can be obtained by accurate measurement of the time varying pressure field.

In the last fifteen years, deep-ocean bottom pressure measurements have been conducted in several studies on ocean tides (Filloux 1971, 1980; Zetler et al. 1975), the ocean eddy pressure field (Brown et al. 1975), weather-induced bottom pressure fluctuations

Corresponding author address: Dr. D. Randolph Watts, University of Rhode Island, Graduate School of Oceanography, Narragansett Bay Campus, Narrangansett, RI 02882-1197.
(Beardsley et al. 1977), and the performance of the pressure instruments themselves (Snodgrass et al. 1975). The most common pressure sensors used in the above studies, have been strain gauges (Wunsch and Wimbush 1977), Vibrotron sensors (Wimbush 1977), metal Bourdon tubes (Filloux 1970; Mofjeld and Wimbush 1977), and quartz-crystal transducers (Snodgrass et al. 1975).

Although the requirement of adequate sensitivity and short-term stability is of great importance, the chief difficulty in dealing with pressure instruments is the instrumental noise of low frequency, i.e., drift, whose magnitude typically increases with applied pressure. Consequently, it has been most difficult to measure bottom pressures of the deep ocean. The drift contaminates the observed spectrum most at low frequencies. (A simple example is that a linear drift would add a red noise spectrum of slope $f^{-2}$.) Consequently, earlier studies with deep pressure gauges have tended to focus on tides or other relatively high frequency (less contaminated) portions of the data.

This paper has two main purposes:

1) To present results from several deployments of Digiquartz pressure transducers in water depths around $4000 \mathrm{~m}$ and examine whether the drift is reproducible and predictable, and whether the amount of drift may be reduced by "preconditioning" the sensors prior to deployment. 
2) To present our method of drift estimation and removal from the records, and a method to estimate the residual uncertainty in the "dedrifted" records.

We demonstrate that the residual uncertainty is low enough $(\sim 0.02 \mathrm{db})$ that the dedrifted records are suitable for study of mesoscale frequency dynamical pressure signals in the deep ocean.

In the following, we briefly present the experimental setting and measurements, and we describe the pressure and temperature sensors. In section 4 we discuss the observed pressure drifts in relation to sensor construction, clock-frequency drift and to prior history of pressurization. In sections 5 and 6 we present our techniques to model and remove the drift, and we estimate the uncertainties in the drift removal, i.e., the accuracy of the final records. As a consistency check, in section 7 we compare geostrophic currents calculated from measured pressure differences with directly observed deep currents. A companion paper, (Kontoyiannis and Watts 1990), deals with the scientific interpretation of the pressure records in combination with other inverted echo sounder and current meter data. Section 8 summarizes the results.

\section{Experimental setting and measurements}

As part of our other studies in the Gulf Stream, data were collected using deep-ocean bottom pressure and temperature sensors northeast of Cape Hatteras in several deployment periods between September 1983 and March 1987. The deployment sites and the overall study area are shown in Fig. 1. The data records in this article are labeled by (i) the last two digits of the year in which the instrument was recovered, and (ii) the site designation indicated in Fig. 1. For example, 84B2 means the data record collected in 1984 at site B2.

In the period from September 1983 to March 1987 , seven different pressure sensors (Table 1) were used for a total of 17 deployments at 12 sites (Fig. 2). We had an instrument recovery rate of $100 \%$ for these deployments, however due to an electronics failure in one case and a malfunction of one sensor in two of its deployments, as described in section $4 \mathrm{~b}$, three pressure records were missing or unsatisfactory. Thus we have 14 deployments with successful pressure records. Complete records were obtained for all 17 deployments of the temperature sensors.

\section{Description of the sensors}

\section{a. Pressure sensor and mounting}

All sensors we have used are Digiquartz 6000 psi range transducers manufactured by Paroscientific, Inc. A detailed description of them is given by Paros (1976) and by Wearn and Larson (1982). Briefly, the key sensing element in the pressure transducer is an oscillating beam-shaped quartz crystal, piezoelectrically induced to vibrate in its lowest resonant flexural mode by an oscillator circuit. The oscillation frequency of the crystal varies with the stress load transmitted to it through a lever arm attached to either a bellows or a Bourdon tube (Fig. 3). The bellows or Bourdon tube is pressurized at the full ambient pressure of the ocean via a long, thin capillary tube filled with mineral oil. The measurement of fluid pressure is made by counting (averaging) the output frequency of the oscillator cir-

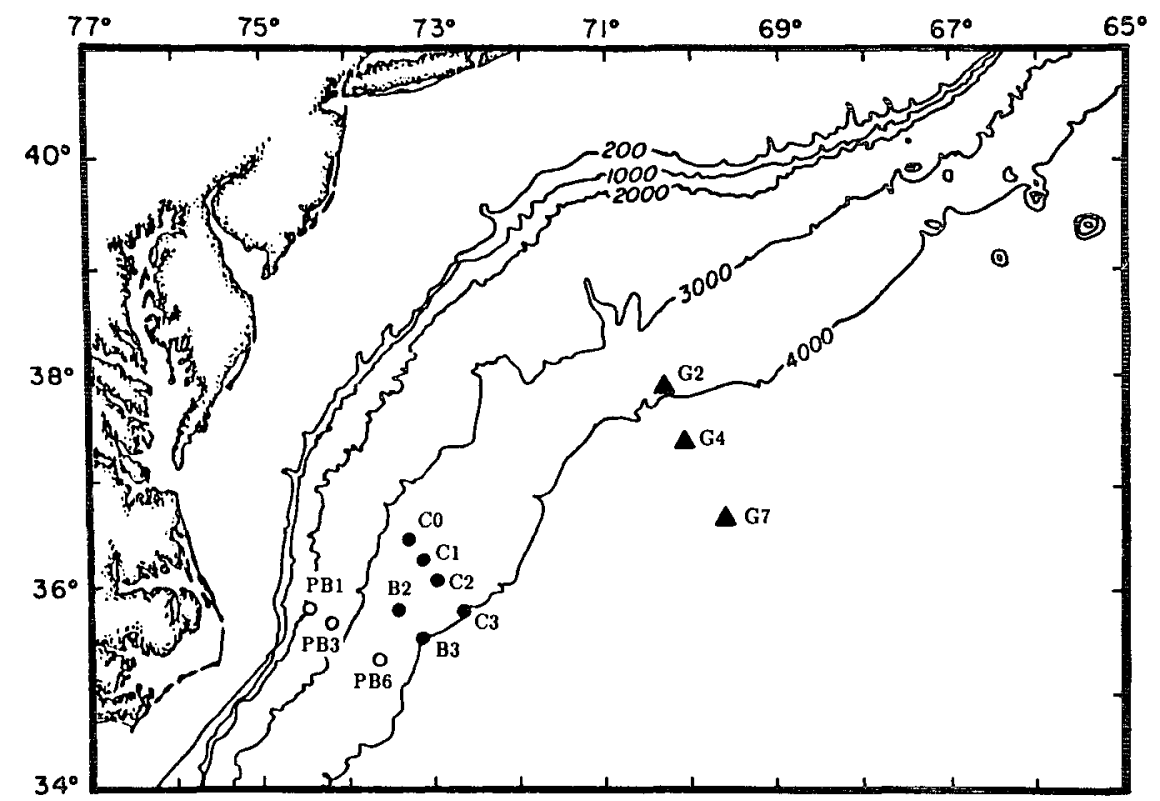

FIG. 1. Study area and deployment sites under the Gulf Stream. Cape Hatteras is near the lower left corner. Bathymetric contours are in meters. 
TABLE 1. Pressure sensors used.

\begin{tabular}{crrrl}
\hline \hline & $\begin{array}{c}\text { Serial } \\
\text { number }\end{array}$ & Model & $\begin{array}{c}\text { Working range } \\
(\mathrm{db})\end{array}$ & \multicolumn{1}{c}{ Type } \\
\hline 1 & 8181 & $75 \mathrm{~K}-002$ & $0-3450$ & Bellows \\
2 & 8180 & 75000 & $0-3450$ & Bellows \\
3 & 17848 & $76 \mathrm{~KB}-032$ & $0-4100$ & Bourdon-tube \\
4 & 17849 & $76 \mathrm{~KB}-032$ & $0-4100$ & Bourdon-tube \\
5 & 17911 & $76 \mathrm{~KB}-032$ & $0-4100$ & Bourdon-tube \\
6 & 18426 & $76 \mathrm{~KB}-032$ & $0-4100$ & Bourdon-tube \\
7 & 19327 & $46 \mathrm{~K}-032$ & $0-4100$ & Bourdon-tube \\
\hline
\end{tabular}

cuit over a period set to be $1 / 2$ hour in these deployments.

The pressure sensors were powered and controlled by Sea Data Corp. model XP35 electronics cards installed in inverted echo sounders (IESs). The IES circuitry and mooring configuration are described by Chaplin and Watts (1984). These instruments were tethered less than $1 \mathrm{~m}$ above the ocean floor, in order to have minimal vertical motion of the instrument in response to bottom currents; we estimate less than 0.4 $\mathrm{cm}$ vertical excursion in the peak deep current speeds $\left(\sim 25 \mathrm{~cm} \mathrm{~s}^{-1}\right)$ observed in our work area.

Another potential concern for bottom pressure measurements is the stability of the mounting on the sea floor. Most evidence indicates no tendency in these deployments for the anchors to sink into the mud or for the bottom to slump downslope: all but three of the observed pressure drifts discussed in the following section are toward the lower (rather than higher) pressures. Moreover, the acoustic travel times $(\tau)$ measured simultaneously on these IESs show no indication of depth change, although only depth changes larger than 1-2 $\mathrm{m}$ would likely be noticed in the $\tau$ records.

\section{b. Temperature sensor}

Because temperature also affects the oscillation frequency of the quartz crystal in the pressure sensor, it is essential to independently measure the temperature of the crystal. A thermistor (Yellow Springs International Corp., model 44032) was placed as close as possible to each sensor. The thermistor was powered and controlled by Sea Data Crop. model DC37 electronics cards installed in the IESs. This circuitry produces an output frequency that varies with the temperature-dependent resistance of the thermistor.

\section{c. Time base and recording}

The half-hourly period, over which we measure the output frequency of the pressure and temperature sensors, was controlled by a quartz crystal clock in the IES; the circuitry is described by Chaplin and Watts (1984). If the counting period drifts by some unknown amount, the change in counts of the pressure sensor frequency is unavoidably interpreted as a pressure drift. The stability of the crystal (JAN Crystals, model HC33/ U AT cut $4.194304 \mathrm{MHz}$ ) and timing circuitry used in these deployments was reported by the company to be $25 \mathrm{ppm} /{ }^{\circ} \mathrm{C}$ and $20 \mathrm{ppm}$ in the first year. However, these stability specifications are not as good as they ought to be; these crystals were mistakenly used as a less expensive replacement for a better crystal. The quartz crystals had all been baked at elevated temperatures and aged before deployment; nevertheless, clockfrequency drift may be responsible for the observed drift in some of the measured pressures when the drift range is small. (After these deployments, we discovered the error and upgraded the time bases.) The preferred stability of the time base is $0.5 \mathrm{ppm}$.

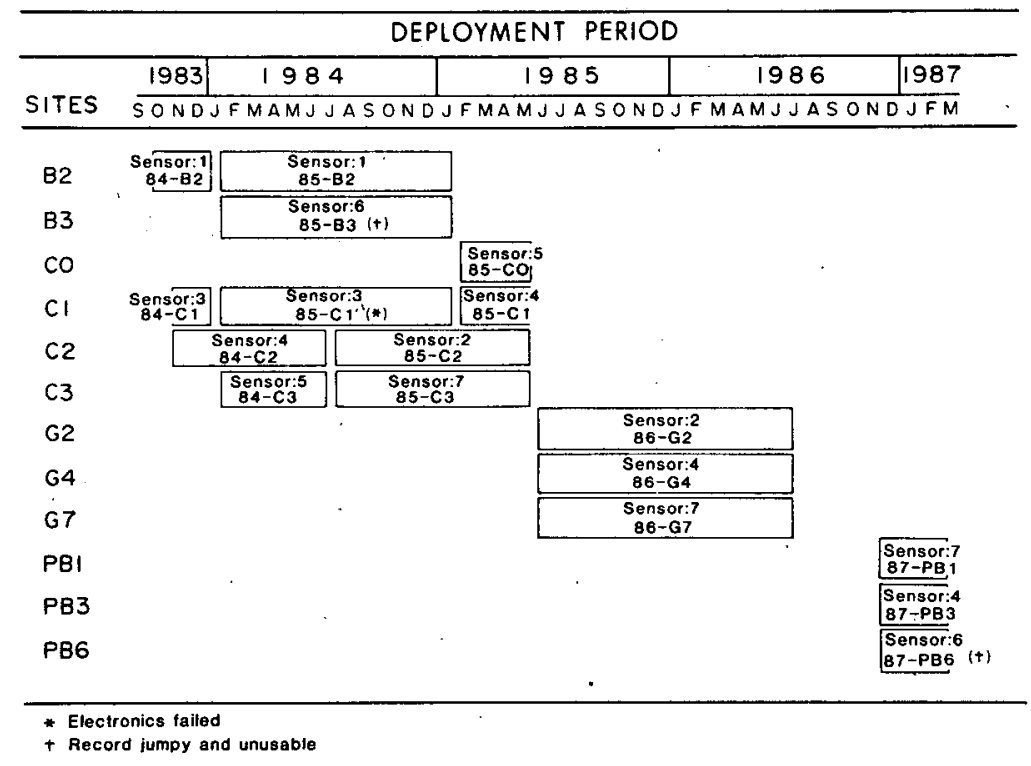

FIG. 2. Deployment periods for pressure sensors at various Gulf Stream sites. 


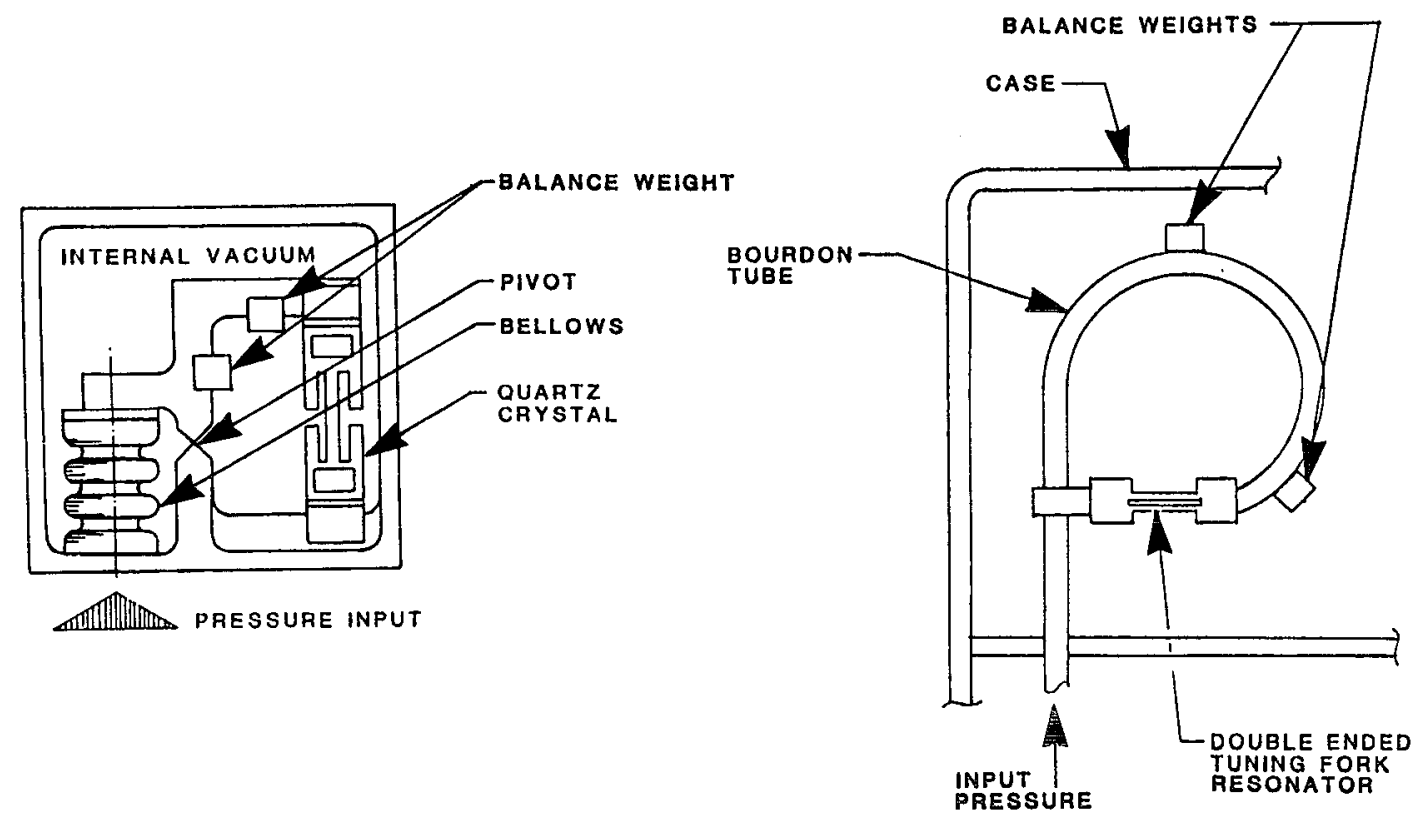

FIG. 3. Schematics of the Digiquartz pressure sensors (courtesy of Paroscientific, Inc.). In the left of the figure is shown the bellows-type sensor and in the right the Bourdon-tube sensor. Each sensor is connected to the environment through a capillary tube filled with mineral oil. Increasing pressure respectively decreases and increases the tension on the quartz crystal of the bellows and Bourdon transducers.

All the data were recorded digitally on the IES data cassettes using a Sea Data model 610 recorder.

\section{Observed drifts of pressure sensors}

\section{a. General description of performance}

In many records a long-term drift is apparent when we remove the mean and the tides. Plots of the detided pressures and superimposed drift-curves are shown in Fig. 4. Several features are common to these records: 1) During the first few hours ( $\leqslant 12 \mathrm{~h}$ ) there is a rapid slewing toward higher pressure readings as the sensors come to thermal equilibrium at the ocean bottom. 2) During the next 3 to 12 months of deployment there is a drift of a few tenths of a decibar, between 0.2 and $0.85 \mathrm{db}$ in the worst six records, with rate decreasing with increasing time. 3 ) Superimposed on the drift is the ocean pressure signal, with obvious 5- to 30-day periodicities and 0.1 - to $0.2 \mathrm{db}$ pressure changes; these are the dynamic pressure signals of central scientific interest that we wish to study uncontaminated by drift. 4) There is high-frequency variability of roughly \pm 0.02 $\mathrm{db}$, which exceeds measurement noise $(\leqslant 0.001 \mathrm{db})$ or our estimates of instrument depth variation.

Table 2 summarizes the drift characteristics found for all the deployments; for simplicity, only the total change during the first 6 days and the total change from start to end of the record are listed. Several other factors are also listed that could be expected to influence the amount of drift. These include the sensor construc- tion (bellows vs Bourdon tube), whether the sensor was "preconditioned" to high pressure for some period before deployment, and the ambient pressure ( 3340 to $4400 \mathrm{db}$ ) during the deployment. We also list the pressure drift caused by clock-frequency drift in those deployments for which we were able to independently determine the latter. In the following discussion we relate the amount of drift to these factors, although we must caution that we have very few replicate examples.

\section{b. Factors influencing performance}

In this section we provide an overview of the drift characteristics shown in Table 2.

Two bellows sensors (labeled 1 and 2 in Table 1) were used in four deployments and returned four records, all of which showed significant drift $(\sim 0.21$ to $0.85 \mathrm{db}$ ), of opposite sign for the two sensors. The sense of the drift was reproduced in their second deployments, but did not improve much with preconditioning, and the magnitude is much larger than the clock-induced component. The characteristic decaytime and amplitude of the drift changes greatly from sensor to sensor and from one deployment to another of the same sensor for bellows and Bourdon-tube sensors.

One of the five Bourdon-tube sensors (sensor 6 ) recorded numerous discontinuous jumps of varying size and sign in both of its deployments, although this was difficult to detect in the laboratory. After the second deployment it was returned to the manufacturer, and 

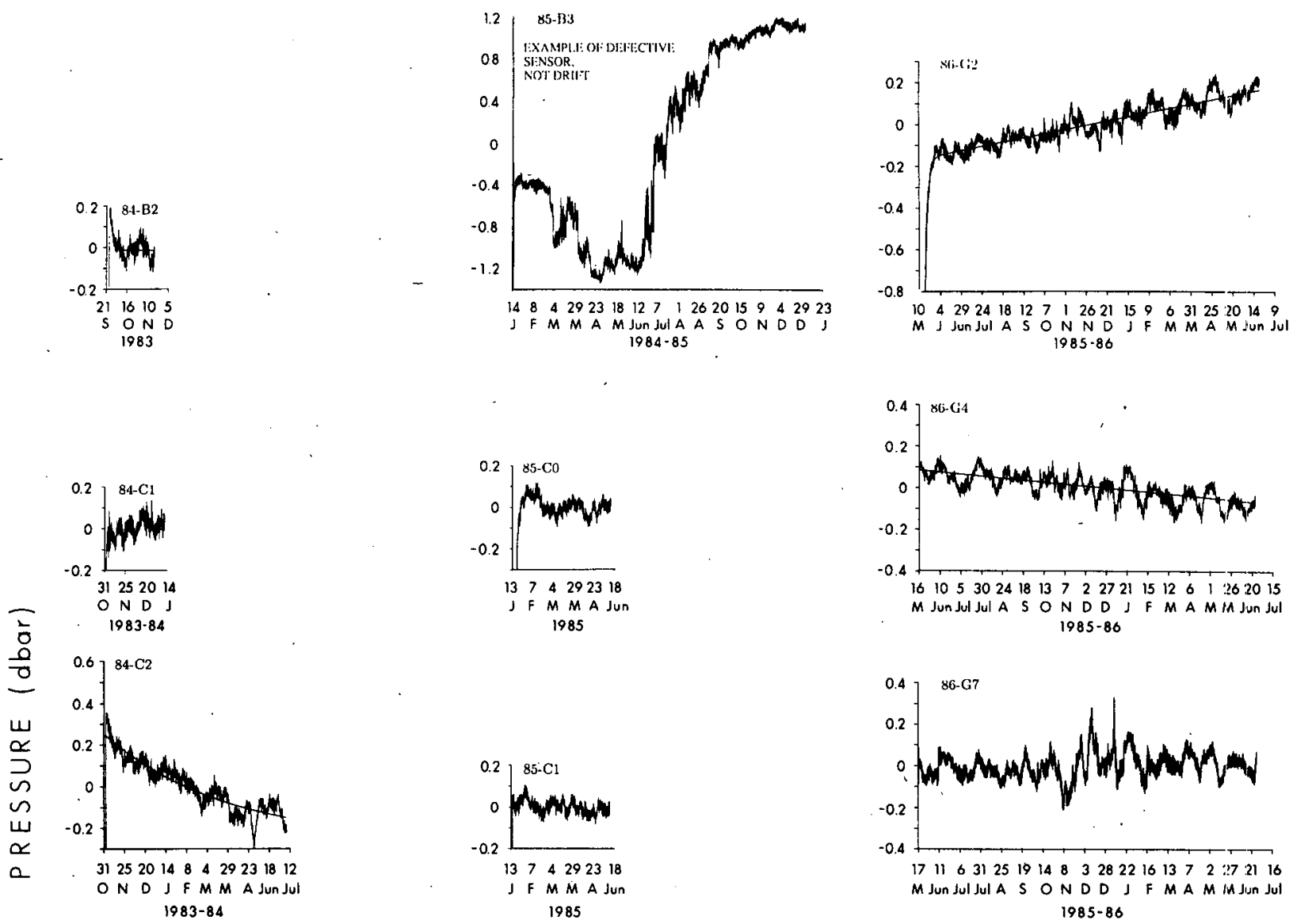

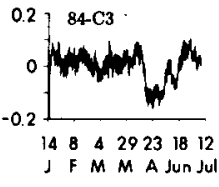

1984

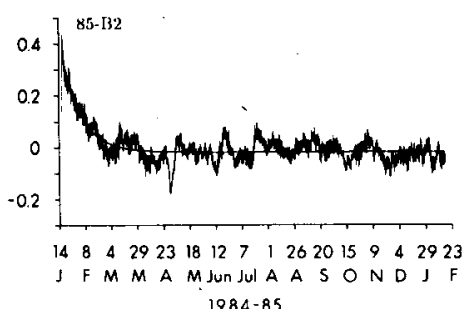

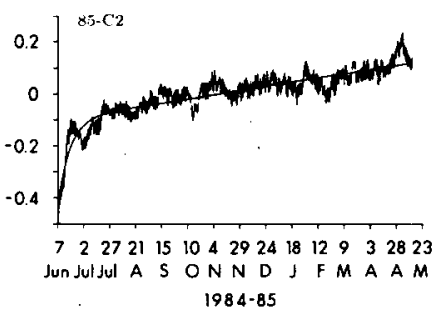

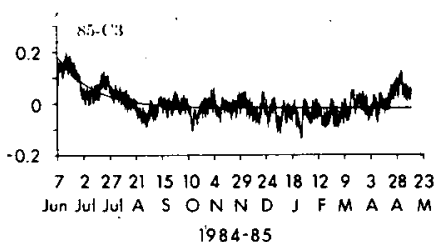

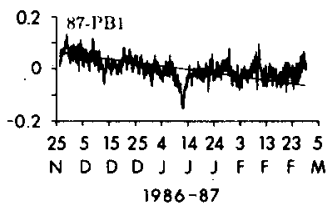

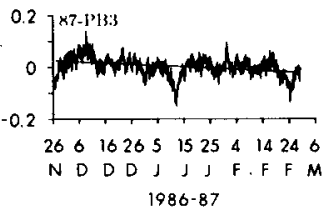

FIG. 4. Original pressure records with tides removed. The fitted drift curves are superimposed. The sensor malfunction illustrated in record $85-\mathrm{B} 3$ is not drift, as explained in section 4 .

the problem was traced to marginal electrical contacts at the sealed quartz crystal. The other four Bourdontube sensors, used in eleven deployments, produced ten records; in the second deployment of sensor 3 (record $85-\mathrm{Cl}^{\prime}$ '), the electronics failed shortly after launch.

Three of the four successful Bourdon sensors (all except sensor 5) showed a pressure drift in their first deployment. Two of them (sensors 4 and 7 ) were not preconditioned and the amount of their drift exceeded that which could be accounted for by clock-frequency drift. The third sensor ( sensor 3 ) was preconditioned and its small total drift $(\sim 0.1 \mathrm{db})$ may have been 
TABLE 2. Drift characteristics for each deployment.

\begin{tabular}{|c|c|c|c|c|c|c|c|c|c|c|c|}
\hline \multirow[b]{4}{*}{ Record } & & & \multirow{2}{*}{\multicolumn{2}{|c|}{ Preconditioning }} & \multirow{2}{*}{\multicolumn{3}{|c|}{ Deployment }} & \multicolumn{4}{|c|}{ Drift (db) } \\
\hline & \multirow{2}{*}{\multicolumn{2}{|c|}{ Sensor }} & & & & & & \multicolumn{2}{|c|}{ Observed } & \multicolumn{2}{|c|}{ Caused by clock } \\
\hline & & & \multirow{2}{*}{$\begin{array}{l}\text { Duration } \\
\text { (months) }\end{array}$} & \multirow{2}{*}{$\begin{array}{l}\text { Pressure } \\
\text { (db) }\end{array}$} & \multirow[b]{2}{*}{ Dates } & \multirow{2}{*}{$\begin{array}{l}\text { Duration } \\
\text { (months) }\end{array}$} & \multirow{2}{*}{$\begin{array}{c}\text { Pressure } \\
\text { (db) }\end{array}$} & \multirow{2}{*}{$\begin{array}{l}\text { Initial } \\
6 \text { days }\end{array}$} & \multirow{2}{*}{$\begin{array}{l}\text { Entire } \\
\text { record }\end{array}$} & \multirow{2}{*}{$\begin{array}{l}\text { Initial } \\
6 \text { days }\end{array}$} & \multirow{2}{*}{$\begin{array}{l}\text { Entire } \\
\text { record }\end{array}$} \\
\hline & Number & Type & & & & & & & & & \\
\hline $84-B 2$ & 1 & Bellows & 24 & 3200 & Oct 83-Jan 84 & 3 & 3625 & -0.15 & -0.21 & \multicolumn{2}{|c|}{ unknown } \\
\hline $85-\mathrm{B} 2$ & 1 & Bellows & 3 & 3625 & Jan $84-\operatorname{Jan} 85$ & 12 & 3645 & -0.17 & -0.37 & +0.01 & +0.065 \\
\hline $85-\mathrm{C} 2$ & 2 & Bellows & 4 & 3900 & Jun 84-May 85 & 11 & 3730 & +0.15 & +0.48 & -0.001 & -0.035 \\
\hline $86-G_{2}$ & 2 & Bellows & 11 & 3730 & May $85-J u n ~ 86$ & 12 & 3870 & +0.60 & +0.85 & -0.002 & -0.04 \\
\hline $84-\mathrm{Cl}$ & 3 & Bourdon & 3 & 1400 & Nov 83-Jan 84 & 2 & 3514 & +0.03 & $+0.10^{+}$ & \multicolumn{2}{|c|}{ unknown } \\
\hline $85-\mathrm{Cl}^{\prime}$ & 3 & Bourdon & 2 & 3514 & Jan $84-$ Jan 85 & 12 & $\#$ & $*$ & * & \multicolumn{2}{|c|}{-} \\
\hline $84-\mathrm{C} 2$ & 4 & Bourdon & - & - & Nov 83-Jun 84 & 8 & 3730 & -0.12 & -0.45 & -0.004 & -0.07 \\
\hline $85-\mathrm{Cl}$ & 4 & Bourdon & - & - & Jan 85-May 85 & 5 & 3530 & \multicolumn{2}{|c|}{ none } & \multicolumn{2}{|c|}{ unknown } \\
\hline 86-G4 & 4 & Bourdon & 5 & 3530 & May $85-J u n ~ 86$ & 12 & 4240 & -0.02 & -0.16 & \multicolumn{2}{|c|}{ unknown } \\
\hline 87-PB3 & 4 & Bourdon & - & - & Nov $86-$ Feb 87 & 3 & 2665 & -0.01 & -0.05 & \multicolumn{2}{|c|}{ unknown } \\
\hline $84-\mathrm{C} 3$ & 5 & Bourdon & - & - & Jan 84-Jun 84 & 6 & 3990 & \multicolumn{2}{|c|}{ none } & \multirow{2}{*}{\multicolumn{2}{|c|}{$\begin{array}{l}\text { unknown } \\
\text { unknown }\end{array}$}} \\
\hline $85-\mathrm{CO}$ & 5 & Bourdon & - & - & Jan 85-May 85 & 5 & 3340 & 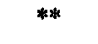 & $*$ & & \\
\hline $85-B 3$ & 6 & Bourdon & - & - & Jan 84-Jan 85 & 12 & $\dagger$ & + & $\dagger$ & \multicolumn{2}{|c|}{ - } \\
\hline 87-PB6 & 6 & Bourdon & 一 & - & Nov 86-Feb 87 & 3 & $t$ & $\dagger$ & $\dagger$ & \multicolumn{2}{|c|}{ - } \\
\hline $85-C 3$ & 7 & Bourdon & - & - & Jun 84-May 85 & 11 & 3990 & -0.08 & -0.21 & -0.02 & -0.075 \\
\hline $86-G 7$ & 7 & Bourdon & 11 & 3990 & May $85-J u n ~ 86$ & 12 & 4435 & \multicolumn{2}{|c|}{ none } & 0.0 & 0.0 \\
\hline 87-PB1 & 7 & Bourdon & - & - & Nov $86-F e b 87$ & 3 & 1950 & -0.02 & -0.08 & \multicolumn{2}{|c|}{ unknown } \\
\hline
\end{tabular}

+ Not dedrifted because record is very short.

* Electronics failed.

*** $+0.15 \mathrm{db}$ drift in first two days.

${ }^{\dagger}$ Record jumpy and unusable.

caused by the clock. The drift of each Bourdon-tube sensor in its second and subsequent deployments was either undetectable or had different shape and smaller magnitude than the first deployment and could possibly all be due to clock-frequency drift. We take this as a very promising result for the Bourdon sensors, since the clock time-base is more easily upgradable than the pressure transducers themselves.

To briefly summarize the performance discussed above:

- Bourdon-tube sensors performed better than bellows sensors.

- Preconditioning in the laboratory or prior deployment of the Bourdon-sensors substantially reduced or eliminated the drift in subsequent deployments.

- The drift characteristics are not reproducible from one deployment to another.

\section{Method of drift estimation and removal}

\section{a. Introduction to drift modeling}

Historically, investigators have modeled the drift of various pressure sensors by either a power-law $[\sim(t$ $\left.\left.-t_{0}\right)^{\beta}, 0<\beta<1\right]$, logarithmic $\left[\sim \ln \left(t-t_{0}\right)\right]$ or exponential $\left\{\sim \exp \left[-\alpha\left(t-t_{0}\right)\right]\right\}$ dependence on time, $t$, after initial pressurization at $t=t_{0}$. Although the exact cause of the drift is unknown, it is believed to result from mechanical creep of materials subjected to high stress. The above three dependencies have been used to describe creep in laboratory and geophysical studies, as has been reviewed by Wunsch and Wimbush (1977), Filloux (1980), and Wearn and Larson (1982).

It had been hoped and asserted (Wearn and Larson 1980 ) that by careful measurement of drift characteristics of a sensor in the laboratory, the drift curve for it in an ocean deployment might be accurately predicted. Skepticism has probably always been appropriate about applying such predictions, because the drift processes may not be reversible or reproducible. Moreover, for the deep-ocean pressure sensors it has not yet been practical to monitor the drift in the laboratory at the required $\sim 1 \mathrm{ppm}$ accuracy for long time periods. In one of the best attempts yet made (Wearn and Larson 1980), the required level of absolute pressure and temperature stability was not achieved even by their high-quality calibration instruments.

\section{b. Drift estimation and removal}

In these deployments, the approach to drift estimation has been to make least-squares fits of the above three mathematical models to the records. Since most of the records are long compared to the time scales of 
the deep-ocean pressure variability, the ocean pressure signal will tend to average out in estimating the drift.

A detailed comparison of the relative merits of the above mathematical models in the drift estimation is presented by Watts and Kontoyiannis (1986) and shows that the exponential law has the best overall performance. The exponential drift curves have in general smaller rms deviations from the original data than the logarithmic and power-law curves; the latter two, when plotted, are virtually indistinguishable. The better performance of the exponential law compared to the logarithmic law is confirmed when we use differences of the dedrifted pressures between sites to calculate geostrophic bottom currents, as in the example of section 7 . An undetectable residual drift in our dedrifted pressure records would produce a detectable drift in the geostrophic bottom currents. For some of the pairs of our sites, the geostrophic currents calculated from logarithmically dedrifted pressures do show a drift in the first few days, whereas, in all of the pairs of our sites, the geostrophic currents calculated from exponentially dedrifted pressures have no noticeable drift. The exponential law appears to describe the drift of these records best, regardless of whether it was caused by the pressure transducer or may have been significantly influenced by time-base frequency drift.

The exponential curves were preferred for the drift removal of all the records except for 85-C2 and 86-G2 (both obtained with bellows sensor 2) for which an exponential-linear curve seemed to be required. The mathematical representation of the drift was

$$
P_{\text {drif }}=P_{1}\left[1-\exp \left(P_{2} t\right)\right]+P_{3}+P_{4} t
$$

where $P_{4}=0$ except for sensor 2 . The $P_{i}$ are free parameters determined by the nonlinear regression subroutine and $t$ is time in hours. The time origin of the drift was assumed to be the time after launch when the instrument was roughly halfway to the sea floor, i.e., 1 hour before the first sample on the bottom. We also removed the first 12 hours of data ( 24 pts) after the instrument landed on the sea floor because during this time the sensors inside the glass instrument housing were still coming to thermal equilibrium, causing these initial measurements to change rapidly. Hence the time origin was 13 hours before the first data point used. Tides were removed by response analysis (Munk and Cartwright 1966). The final pressure records (detided and dedrifted), which are our best estimate of the true deep-ocean pressure signal, were calculated by subtracting the fitted $P_{\text {drif }}$ curve from its respective detided set of measurements at each half-hourly data point.

\section{Estimated accuracy of final pressure records}

\section{a. General remarks}

We now attempt to estimate the uncertainty in the drift-removal procedure, or equivalently, to estimate the long-term accuracy of the residual records. This is a separate question from that of the absolute accuracy of the mean pressure, which is about $\pm 1.5 \mathrm{db}$. The absolute accuracy is not at issue here, because the absolute depth of the instrument site relative to the geoid is not known either.

It is difficult to estimate the accuracy of the drift curves for these records. Each has a mixture of two unknown signals that differ for each site: the ocean pressure signal plus the drift. Some records are from different time periods, and others coincide in time but are from different sites $(\sim 15$ to $50 \mathrm{~km}$ apart $)$ with coherent, but different ocean pressure signals. We have no independent way to determine either the ocean signal or the drift signal exactly, but the methods we have used to separate them essentially assume that they have different spectral characteristics.

Since the rate of drift decreases greatly with increasing time, another distinction is that the longer duration records (especially their later months) have a relatively smaller proportion of their variance associated with drift errors. Hence, they become more dominated by the ocean signal.

\section{b. Two methods to estimate uncertainties}

We take advantage of these differences to estimate the errors in two ways. In the first method, at two sites we have pairs of records each several months long, in which one sensor recovery was followed soon afterwards by another deployment at the same site. Figure 5 shows these records, $84-\mathrm{C} 2$ and $85-\mathrm{C} 2$ at site $\mathrm{C} 2$, and records $84-\mathrm{C} 3$ and $85-\mathrm{C} 3$ at site $\mathrm{C} 3$. The drift-rernoval error at the end of one record is probably small compared to that at the beginning of the subsequent record, since it seems reasonable to expect that the magnitude of error is roughly proportional to the amount of drift being removed. Hence, any pressure "jump" occurring between the records gives an estimate of the size of drift-removal error that characterizes the beginning of a record. The "jump" magnitudes are about $0.02 \mathrm{db}$ at site $\mathrm{C} 2$ and $0.06 \mathrm{db}$ at cite $\mathrm{C} 3$ (listed in Table 3). However, we should emphasize that the slope and size of this "jump" is smaller than many of the observed ocean pressure changes in the continuous records (Fig. 5), and may be real rather than a drift removal error.

The second method to estimate the error was to regress the exponential law on shorter segments of the records. These segments have the same true drift curve, but our estimate of it will differ for different segrnents due to the "contamination" by the ocean pressure signal. An inference of how much the ocean signal causes the regressed drift curve to differ from the true clrift can be taken from the differences between the regressed drift curves obtained from different segments of the record.

We use the second method only on the six longest records ( 7 to 12 months), because it was felt that di- 

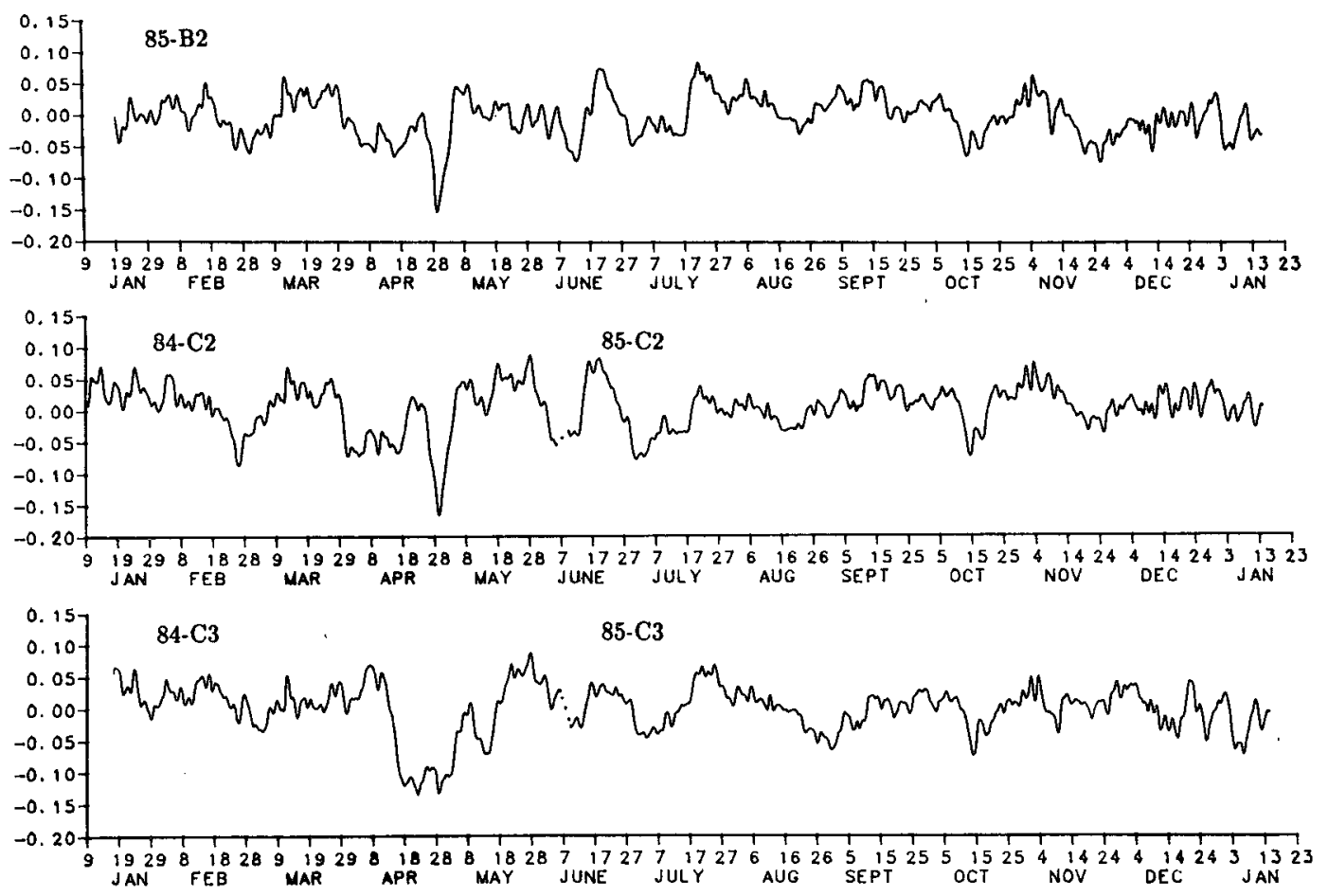

FIG. 5. Detided, dedrifted pressure records from sites B2, C2, and C3 for January 1984 to January 1985.

At site B2 the record is continuous; at sites C2 and C3 the sensors changed in June 1984.

viding the records into segments shorter than 3 months was inadvisable, given the obviously energetic ocean pressure signals at shorter periodicities. Each of the six records was divided into two segments at a point which had a pressure near the overall drift curve, to avoid introducing new end effects. An exponential curve was fitted to the drift for each segment. Then we computed the offsets between these fitted curves at the break-point where one joins another. At the same point, we also computed the differences between the curves fitted on the segments and the curve originally fitted on the whole record. The results of these calculations are summarized in Table 3. The magnitudes of the offsets range from 0.000 to $0.053 \mathrm{db}$; the rms offset of all the break-points was $0.023 \mathrm{db}$.

\section{c. Discussion of drift uncertainty estimates}

Although the rms uncertainty $(0.023 \mathrm{db})$ in removing drift is estimated following a statistical approach (Table 3), it does not represent a random high frequency error, but implies that our final pressure records might still contain a slow monotonic drift which makes the detided and dedrifted signal differ from the true ocean signal by as much as $\pm 0.023 \mathrm{db}$. We now argue that the offsets between the above exponential-law regressions on segments of each given record are probably overestimates of the uncertainty of the drift regression on the full record. Two reasons support this contention:
1) The offsets occur at the beginning of each segment, where the regressed curve has its maximum amplitude and probably maximum error. However, in the regression curve for the full record, this corresponding time is not at the beginning, but farther out in the tail of the true drift curve, where the drift rate is slower and the error should be smaller.

2) The full record regression curve is 2 to 4 times as long as the independent segments, with consequently greater degrees of freedom and more confidence in "averaging out" the ocean signal. If the ocean signal has roughly a normal distribution given sufficient degrees of freedom, then doubling (or quadrupling) the segment length would improve the removal of ocean signal from the drift by a factor of $2^{1 / 2}$ (or 2 , respectively).

Overall, we estimate that these fitted drift curves have only about $0.016 \mathrm{db}$ uncertainty for records at least a year long.

\section{Example of geostrophic currents}

Geostrophy describes the balance between horizontal pressure gradient and Coriolis force on a current. For low-frequency large-scale oceanic and atmospheric motions, it has been documented that the flow field is predominantly geostrophic (e.g., Johns et al. 1989). In this deep-ocean example, because we can not measure the absolute pressure field relative to the geoid, 
TABle 3. Pressure offsets between drift curves estimated on different, sequential records (a) and on segments of the same record (b); estimated accuracy of final, "dedrifted" pressure records.

(a) Pressure offsets between different, sequential records

\begin{tabular}{cccr} 
Records & $\begin{array}{c}t_{a} \\
\text { (months) }\end{array}$ & $\begin{array}{c}\mathbf{t}_{b} \\
\text { (months) }\end{array}$ & $\begin{array}{c}\Delta P \\
(\mathrm{db})\end{array}$ \\
\hline 84-C2 and 85-C2 & 8 & 11 & 0.02 \\
$84-\mathrm{C} 3$ and 85-C3 & 6 & 11 & -0.06 \\
\hline
\end{tabular}

$t_{a}:$ Length of first segment or record

$t_{b}$ : Length of second segment or record

$\Delta P$ : Pressure offset between drift curves of two segments at join-point or of two full records

(b) Pressure offsets between segments of the same record

\begin{tabular}{|c|c|c|c|c|c|}
\hline Record. & $\begin{array}{c}t_{a} \\
\text { (months) }\end{array}$ & $\begin{array}{c}t_{b} \\
\text { (months) }\end{array}$ & $\begin{array}{c}\Delta P \\
(\mathrm{db})\end{array}$ & $\begin{array}{l}\Delta P_{a} \\
(\mathrm{db})\end{array}$ & $\begin{array}{l}\Delta P_{b} \\
(\mathrm{db})\end{array}$ \\
\hline $85-B 2$ & 4.4 & 8 & -0.015 & 0.013 & -0.002 \\
\hline $85-\mathrm{B} 2$ & 7.4 & 5 & 0.000 & 0.001 & 0.001 \\
\hline $84-\mathrm{C} 2$ & 3 & 4.3 & -0.016 & -0.052 & -0.036 \\
\hline $84-\mathrm{C} 2$ & 4.6 & 2.6 & 0.042 & -0.020 & 0.022 \\
\hline $85-\mathrm{C} 2$ & 2.6 & 8.6 & -0.007 & -0.004 & -0.011 \\
\hline $85-C 2$ & 5.6 & 5.6 & 0.037 & -0.028 & 0.009 \\
\hline $85-\mathrm{C} 2$ & 8.3 & 2.9 & 0.053 & -0.004 & 0.049 \\
\hline $85-\mathrm{C} 3$ & 2.6 & 8.6 & 0.003 & 0.014 & 0.017 \\
\hline $85-\mathrm{C} 3$ & 5.6 & 5.6 & -0.006 & 0.006 & 0.000 \\
\hline $86-G 2$ & 6 & 6 & -0.010 & & \\
\hline \multirow[t]{3}{*}{$86-G 4$} & 6 & 6 & -0.008 & & \\
\hline & \multirow{2}{*}{\multicolumn{2}{|c|}{$\begin{array}{l}\Delta P_{\text {ms }} \text { for above segment end points: } \\
\text { Est. } \Delta P_{\text {drift }} \text { for } 12 \text { month record*: }\end{array}$}} & 0.027 & 0.021 & 0.022 \\
\hline & & & 0.019 & 0.015 & 0.016 \\
\hline
\end{tabular}

* Obtained by dividing by $(2)^{1 / 2}$, because the degrees of freedom are doubled.

$\Delta P_{a}$ : Pressure offset between drift curve of first segment and drift curve of the full record, both evaluated at the end of first segment.

$\Delta P_{b}$ : Pressure offset between drift curve of second segment and drift curve of the full record, both evaluated at the beginning of second segment.

we compare only the time-varying components of the geostrophic and the actual velocity fields.

If $(s, l)$ denotes a horizontal rectangular coordinate system, then the geostrophic relationship states:

$$
V_{g l}^{\prime}=\frac{1}{\rho f} \frac{\partial P^{\prime}}{\partial s}
$$

where $V_{g l}^{\prime}$ is the geostrophic velocity parallel to $l$, and $P^{\prime}$ is the pressure field. The geostrophic current perpendicular to the line $\overrightarrow{\Delta s}$ joining two sites is estimated by differencing the pressures between them and dividing by their distance $|\vec{\Delta} s|$, the density $\rho$ and the Coriolis parameter $f$. This finite difference estimation of the geostrophic currents is compared below to the observed currents perpendicular to $\vec{\Delta} s$, as estimated by the average between two current meters at the end points.

We apply this comparison to the 40-hour low-pass filtered bottom pressure and velocity data at sites B2, $\mathrm{C} 2$ and $\mathrm{C3}$. The results are shown in Fig. 6. The fluctuating geostrophic and observed velocity records span from January 1984 to January 1985, the only period during which we have current meter measurements. Although the currents were measured at $500 \mathrm{~m}$ off the bottom in an area of sloping topography, there is little vertical shear at $3500 \mathrm{~m}$ depth, and corrections to the data accounting for depth differences between measurements have negligible effect.

The differences between these pairs of curves can be entirely attributed to sampling errors introduced by comparing finite-differenced bottom-pressures with averaged end-pairs of bottom currents (detailed error analysis appears in Kontoyiannis 1988). There is no evidence in Fig. 6 of drift in the geostrophic current estimates relative to the observed currents. Moreover, there is no noticeable jump in $V_{g l}^{\prime}$ near day 160 , when new pressure records started at sites $\mathrm{C} 2$ and $\mathrm{C} 3$. If the error $\delta P_{b}$ in dedrifted pressures were as large as 0.02 to $0.06 \mathrm{db}$, the corresponding geostrophic velocity offset, estimated as $2^{1 / 2} \delta P_{b} /(\rho f \Delta s)$, with $\Delta s$ ranging from 40 to $60 \mathrm{~km}$, would be $6-17 \mathrm{~cm} \mathrm{~s}^{-1}$, which is not evident in these records. We take this as supporting evidence that the residual error in removing pressure drift is less than $0.02 \mathrm{db}$.

\section{Summary}

The performance of Digiquartz pressure sensors suitable for deep-ocean deployments has been investigated in fourteen records of 3-12 month duration at 

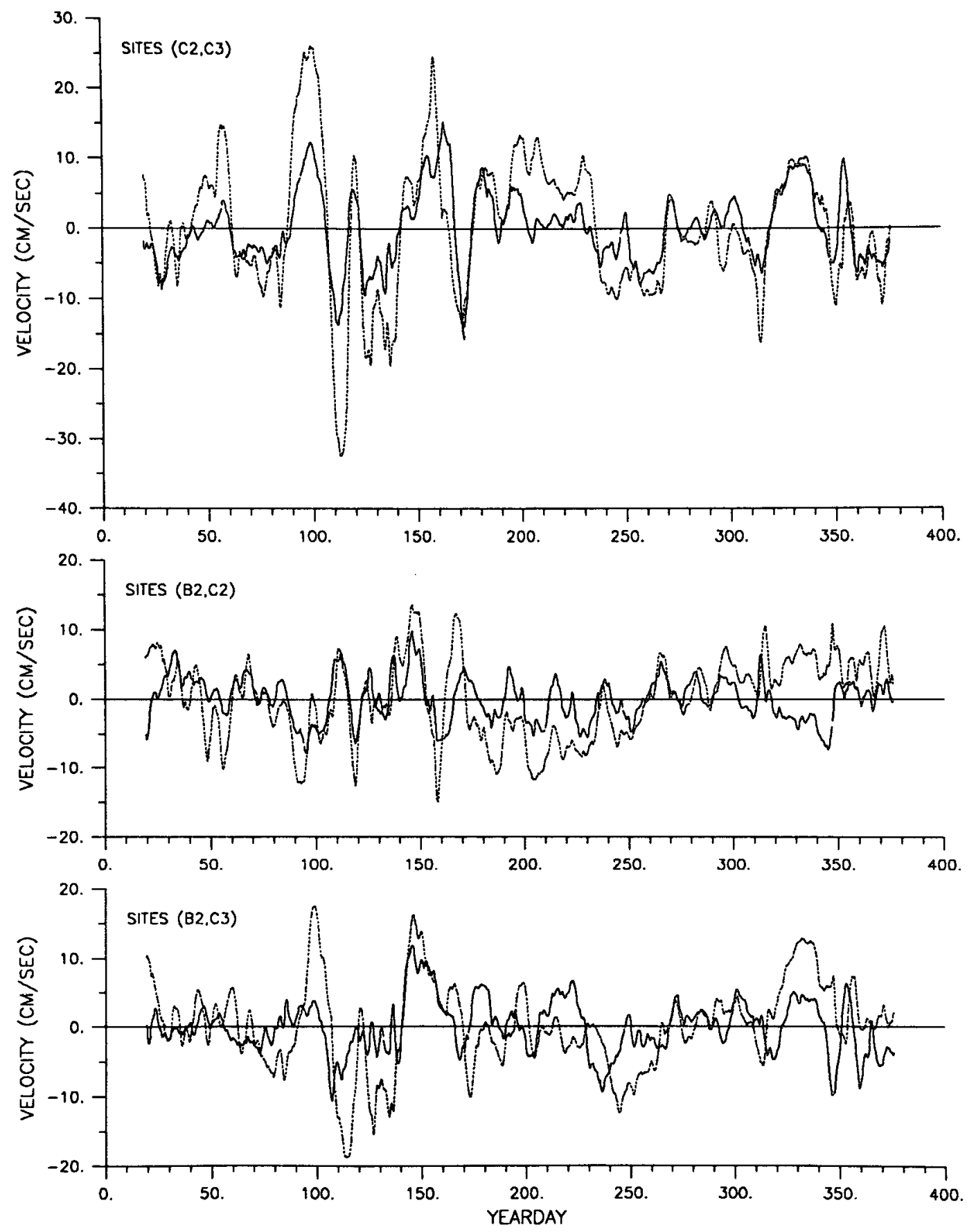

FIG. 6. Comparison of geostrophic (dashed line) and observed (solid line) currents at sites $\mathrm{B} 2, \mathrm{C} 2$, and $\mathrm{C} 3$ (see text).

depths of $3300-4400 \mathrm{db}$. In particular, we have examined the problem of drift in calibration of these sensors: how it is affected by sensor construction and prior history of pressurization, how reproducible it is, how the drift in a record may be estimated and removed, and how accurate the dedrifted records are.

Bourdon-tube actuated sensors performed better (drifted less) than the bellows actuated ones. In fact, once the Bourdon-type sensors had been precondi- tioned, i.e., subjected to deep-ocean pressures for a few months, the amount of drift in subsequent deployments was reduced to the point where in five of six cases we could not distinguish whether the remaining drift $(\leqslant 0.08 \mathrm{db}$ ) should be attrributed to the pressure transducer itself or to the time-base of the frequency-counter; the sixth case drifted $-0.16 \mathrm{db}$ in a year. (We have now upgraded the time-base for subsequent work.) Preconditioning the transducers prior to their first de- 
ployment therefore appears to be a highly valuable effort, eliminating most if not all of the drift.

The drift characteristics do not appear to be predictable beforehand for any given sensor. The size and sign of the drift varied considerably on the first deployment, from +0.85 to $-0.37 \mathrm{db}$ in a year for bellows sensors, and from +0.10 to $-0.45 \mathrm{db}$ for Bourdon sensors. However, on all subsequent depolyments each sensor retained the same sense of drift, and three of the four successful Bourdon sensors drifted toward lower pressures or indetectably. The time-constant of exponential decay varied greatly, by a factor of 40 , from sensor to sensor (and on different deployments of the same sensor, but this may be partially due to clock drifts as mentioned above).

Special methods were developed for estimating and removing the drift from the records, a difficult task in the presence of an ocean-signal that is of similar magnitude and not independently known. Least-squares fits of power-law, logarithmic, and exponential decay laws were made to each pressure record. The exponential drift curve was best, and this was subtracted from the record at each data point. We estimate that our threshold for detecting a drift in a year-long record is about $0.005 \mathrm{db}$ (in this region of relatively energetic subtidal deep pressure fluctuations). We estimate that the uncertainties remaining in our dedrifted pressure records (mean removed) are $\leqslant 0.02 \mathrm{db}$; the error may be possibly somewhat greater than this in the first week of records that had strong drift, and somewhat less in the tails of year-long records.

This error estimate was confirmed by differencing neighboring pairs of bottom pressure records to compute geostrophic currents, and showing that they compare well with directly observed, suitably averaged deep currents. The residual uncertainties in the final dedrifted pressure records are small compared to the deep ocean pressure signal in this region, with typically around $0.7 \mathrm{db}$ tidal and $0.13 \mathrm{db}$ detided amplitudes. The errors will tend to contaminate only the relatively long ( $\leqslant 100 \mathrm{~d}$ ) periodicities in the records. This opens many possibilities for studies requiring knowledge of the deep-ocean pressure signal. For instance, these bottom-pressure gauges in combination with inverted echo sounders to monitor the baroclinic dynamic height of the water column (Hallock et al. 1989); Pickart and Watts (1990) can provide highly accurate definition of variations in the sea-surface height for later comparisons with satellite altimetry data.

Acknowledgments. This study was made under the combined support of NSF Grants OCE82-01222 and OCE85-17746 and ONR Contracts N00014-81C-0062 and N00014-87K-0235. We are pleased to acknowledge helpful comments on an earlier draft by Dr. Frank Gonzalez at NOAA / PMEL, and the careful instrument preparation and field work by $\mathrm{G}$. Chaplin and M. Mulroney. One of the authors (DRW) would like to acknowledge the hospitality of the National Center for
Atmospheric Research while this work was being; completed.

\section{REFERENCES}

Baker, D. J., 1969: On the history of the high seas tide gauge. Woods Hole Technical Memorandum 5-69.

- 1981: Ocean instruments and experimental design. Evoiution of Physical Oceanography, B. A. Warren and C. Wunsch, Eds., MIT Presș, 396-433.

Bane, J. M., and D. R. Watts, 1985: The Gulf Stream east of Cape Hatteras: The current and its events during 1984, AGU Trans., 66, 21 B-08, 1276.

Beardsley; R. C., H. Mofjeld, M. Wimbush, J. A. Vermersch and C. N. Flagg, 1977: Ocean tides and weather-induced bottom pressure fluctuations in the middle-Atlantic bight. J. Geophys. Res., 82, 3175-3182.

Brown, W., W. Munk, F. Snodgrass, H. Mofjeld and B. Zetler, 1975: MODE bottom experiment. J. Phys. Oceanogr., 5, 75-85.

Chaplin, G., and D. R. Watts, 1984: Inverted echo sounder development. IEEE Oceans '84 Proceedings, 1, 249-253.

Filloux, J. H., 1970: Deep-sea tide gauge with optical readout of Bourdon tube rotaion. Nature, 226, 936-938.

- 1971: Deep-sea tide observations from the northeastern Pacific. Deep-Sea Res., 18, 275-284.

- 1980: Pressure fluctuations on the open ocean floor over a broad frequency range: New program and early results. I. Phys. Oceanogr., 10, 1959-1971.

Hallock, Zachariah R., Jim L. Mitchell and J. Dana Thompson, 1989: Sea surface topographic variability near the New England seamounts chain: An intercomparison among in situ cibservations, numerical simulations and GEOSAT altimetry fiom the regional energetics experiment. J. Geophys. Res., 94, 8021-8028.

Johns, E., D. R. Watts and H. T. Rossby, 1989: A test of geostrophy in the Gulf Stream. J. Geophys. Res., 94, 3211-3222.

Kontoyiannis, H., 1988: The role of the pressure field in the dynamics and energetics of the Gulf Stream at $73^{\circ} \mathrm{W}$. MS thesis, University of Rhode Island, Kingston, $95 \mathrm{pp}$.

Gulf Stream at $73^{\circ} \mathrm{W}$. J. Geophys. Res., submitted.

Mofjeld, H. O., and M. Wimbush, 1977: Bottom pressure obsesvations in the Gulf of Mexico and Caribbean Sea. Deep-Sea Res., 24, 987-1004.

Munk, W. H., and D. E. Cartwright, 1966: Tidal spectroscopy and prediction. Philos. Trans. Roy. Soc. London. 259, 533-581.

Paros, J. M., 1976: Digital pressure transducers. Measurements and Data, 10, 74-79.

Pickart, R., and D. R. Watts, 1990: Using the inverted echo sounder to measure vertical profiles of Gulf Stream temperature and geostrophic velocity. J. Atmos. Oceanic Technol., 7, 145-156.

Snodgrass, F., W. Brown and W. Munk, 1975: MODE: IGPP measurements of bottom pressure and temperature. J. Phys. Oceanogr., 5, 63-74.

Watts, D. R., and H. Kontoyiannis, 1986: Deep-ocean bottom pressure and temperature sensors report: Methods and data. Graduate School of Oceanography, University of Rhode Island, Tech. Rep. 86-8, 113 pp.

Wearn, R. B., and N. G. Larson, 1980: The Paroscientific pressure transducer, measurement of its sensitivities and drift. Applied Physics Laboratory, University of Washington, Tech. Rep. APLUW 8011.

- and - 1982: Measurements of the sensitivities and drift of Digiquartz pressure sensors. Deep-Sea Res., 29, 111-134.

Wimbush, M., 1977: An inexpensive sea-floor precision presisure recorder. Deep-Sea Res., 24, 493-497.

Wunsch, C., and M. Wimbush, 1977: Simultaneous pressure velocity and temperature measurements in the Florida Straits. I. Mar. Res., 35, 75-104.

Zetler, B., W. Munk, H. Mofjeld, W. Brown and F. Dormer, 1.975: MODE tides. J. Phys. Oceanogr., 5, 430-441. 